\title{
Paper Title of Case Report: Fatal Skin Lesions
}

Clara F. Jorge ${ }^{1 *}$, Marlene Louro ${ }^{2}$, Sónia Gomes Coelho ${ }^{3}$, Artur Costa $^{4}$, Margarida Ascensão ${ }^{5}$, Leopoldina Vicente ${ }^{6}$

\author{
1,2,4-6Internal Medicine Department Centro Hospitalar Universitário Cova da Beira, Covilhã, Portugal \\ ${ }^{2}$ Internal Medicine Department Centro Hospitalar Universitário Cova da Beira, Covilhã, Portugal \\ ${ }^{3}$ Internal Medicine Department Unidade Local de Saúde da Guarda, Guarda, Portugal
}

DOI: $10.36347 /$ sjams.2022.v10i01.021

| Received: 11.12.2021 | Accepted: 16.01.2022 | Published: 26.01.2022

*Corresponding author: Clara F. Jorge

Internal Medicine Department Centro Hospitalar Universitário Cova da Beira, Covilhã, Portugal

\section{Abstract}

We present a clinical case of a 75-year-old woman hospitalized for localized edema and erythema on the right hemiface, with progressive extension over 30 days. On objective examination, a heliotropic erythema, Gottron's papules and an ulcerated lesion on the right breast were founded. It's important to point out an increase of muscle enzymes in laboratory tests. According to classification criteria of the European League against Rheumatism, and taking into consideration the clinical suspicion of breast cancer, a paraneoplastic dermatomyositis was diagnosed. Highlight that dermatomyositis lesions are pathognomonic despite that they are not always recognized in the patient's first approach.

Keywords: Dermatomyositis, breast cancer, inflammatory myopathies, Gottron.

Copyright $\odot 2022$ The Author(s): This is an open-access article distributed under the terms of the Creative Commons Attribution 4.0 International License (CC BY-NC 4.0) which permits unrestricted use, distribution, and reproduction in any medium for non-commercial use provided the original author and source are credited.

\section{INTRODUCTION}

Idiopathic inflammatory myopathies (IIM) are essentially characterized by inflammation of the muscles and muscle weakness, as well by systemic manifestations. The most common subgroups of IIM in adults are dermatomyositis (DM), polymyositis (PM) and inclusion body myositis (IBM), and in children, juvenile DM (JDM) [1,2].
The classification of Bohan and Peter are outdated and new clinical subgroups emerged and the classification criteria of the European League Against Rheumatism (EULAR) / American College of Rheumatology (ACR) - EULAR / ACR 2017 were developed. The objective of this classification was to elaborate criterias that would allow the diagnosis of IIM using a probability-score, as well as categorizing them in main subgroups (Table 1) [1,2].

Table-1: Components of the 2017 EULAR/ACR classification criteria for adult and juvenile idiopathic inflammatory myopathies $[1,2]$

\begin{tabular}{|l|l|l|}
\hline When no better explanation for the symptoms and signs exists these classification criteria can be used \\
\hline Variable & \multicolumn{2}{|l|}{ Score } \\
\cline { 2 - 3 } & $\begin{array}{l}\text { No muscle } \\
\text { biopsy }\end{array}$ & $\begin{array}{l}\text { No muscle } \\
\text { biopsy }\end{array}$ \\
\hline Age of onset & \multicolumn{2}{|l|}{1.5} \\
\hline Age of onset of first symptom assumed to be related to the disease $\geq 18$ years and & 1.3 & 2.2 \\
\hline Age of onset of first symptom assumed to be related to the disease $\geq 40$ years & 2.1 & 0.7 \\
\hline Muscle weakness & & 0.5 \\
\hline Objective symmetric weakness, usually progressive, of the proximal upper extremities & 0.7 & 1.6 \\
\hline Objective symmetric weakness, usually progressive, of the proximal lower extremities & 0.8 & 1.2 \\
\hline Neck flexors are relatively weaker than neck extensors & 1.9 & 0.9 \\
\hline In the legs, proximal muscles are relatively weaker than distal muscles & \multicolumn{2}{|l}{} \\
\hline Skin manifestations & 3.1 & 3.2 \\
\hline Heliotrope rash & 2.1 & 2.7 \\
\hline Gottron's papules & 3.3 \\
\hline Gottron's sign & 3.7 \\
\hline
\end{tabular}

Citation: Clara F. Jorge, Marlene Louro, Sónia Gomes Coelho, Artur Costa, Margarida Ascensão, Leopoldina Vicente. Paper Title of Case Report: Fatal Skin Lesions. Sch J App Med Sci, 2022 Jan 10(1): 125-129. 
Clara F. Jorge et al; Sch J App Med Sci, Jan, 2022; 10(1): 125-129

\begin{tabular}{|l|l|l|}
\hline Other clinical manifestations & \multicolumn{2}{|c|}{0.6} \\
\hline Dysphagia or oesophageal dysmotility & 0.7 & \multicolumn{2}{|l|}{} \\
\hline Laboratory measurements & 3.9 & 3.8 \\
\hline Anti-Jo-1 (anti-histidyl-tRNA synthetase) autoantibody present & 1.4 \\
\hline $\begin{array}{l}\text { Elevated serum levels of creatine kinase (CK)* or lactate dehydrogenase (LD)* or } \\
\text { aspartate aminotransferase (ASAT/AST/SGOT)* or alanine aminotransferase } \\
\text { (ALAT/ALT/SGPT)* }\end{array}$ & 1.3 & \\
\hline Muscle biopsy features_presence of: & \multicolumn{2}{|l|}{} \\
\hline Endomysial infiltration of mononuclear cells surrounding, but not invading, myofibres & & 1.7 \\
\hline Perimysial and/or perivascular infiltration of mononuclear cells & 1.2 \\
\hline Perifascicular atrophy & 1.9 \\
\hline Rimmed vacuoles & & 3.1 \\
\hline
\end{tabular}

Modified from [1]

*Serum levels above the upper limit of normal.

Clinically, patient exhibit proximal muscle weakness and typical skin lesions including: edema and periorbital heliotrope erythema (heliotropic rash), an erythematous scaly plaques located on the dorsal surface of the extensors of various joints (Gottron's papules), considered a pathognomonic sign in DM. Other less specific lesions may be observed: ill-defined erythematous macules involving the anterior aspect of the neck and the upper chest (V sign), erythema over the upper back (Shawl sign), cutaneous calcinosis, poikiloderma involving the lateral aspects of the thighs (Holster sign) and periungual hyperemia [3].

As DM is a systemic disease, it can affect the lung, in form of interstitial pneumonia in $10 \%$ of cases, as well as the heart inducing valvular disease, heart failure or myocarditis [4]. Oropharyngeal and upper esophageal muscle involvement may result to dysphagia or aspiration, and weakness of the diaphragm and chest wall muscles usually lead in respiratory failure.

The main laboratory findings are the increase of muscle enzymes (alanine aminotransferase, aspartate aminotransferase, creatine phosphokinase, lactate dehydrogenase and aldolase), which have a good relationship with disease activity [4]. An electromyoneurography (EMNG), a muscle biopsy and magnetic resonance imaging are complementary exams that also help in the diagnosis.

\section{Case Report}

We present a female patient with 75 years old, with mild congenital mental deficiency, independent for activities of daily living, was brought by her daughter to the Emergency Department (ED) due to worsening of photodistributed edema and erythema with 1 month of evolution.

The patient already came several times to the EM for the same reasons, and performed blood tests that didn't reveal any changes. Initially, she presented an edema and erythema on the right hemiface, progressing to all face in a week. She denied fever and airway involvement. It was inicially diagnosed a facial cellulitis and was empirically prescribed amoxicillin and clavulanic acid ( $875 \mathrm{mg}+125 \mathrm{mg}$ every 12 hours) associated to a topical corticosteroid, demonstrating a slight improvement. In another emergency admission, she was treat with intramuscular injection of penicillin associated with deflazacort (30 mg per day). Almost a month later, she was hospitalized for deterioration of the clinical state with mixed dysphagia and hoarseness.

At this time, the patient denied any other type of cardiac-respiratory, genitourinary or gastro-intestinal symptoms. She denied relevant history of clinical disease and usual treatment, and knowned drug or food allergies.

On physical examination, stand out a generalized skin rash with heliotropic rash of the face and the "V sign"(Image 1). She also presented an edema with accentuated godet in the limbs with impetiginized lesions. A thickening of the cuticles and telangiectasias of the nail folds were seen, as well as Gottron papules in knees and elbows (Image 2 and 3) and Holster sign (Image 4).

Upon performing the gynecological examination, an ulcerated, adherent, infiltrative and painless lesion on palpation was found, in the upper external quadrant of the right breast, as well as axillary adenopathies on the same side (Image 3). In the rheumatologic examination, a notorious bilateral proximal muscle deficit was found in the lower limbs.

Analytically, was identified an increase of muscles enzymes: creatine kinase (6347 U/L), lactate dehydrogenase (1559 U/L), aspartate aminotransferase (424 UI/L), alanine aminotransferase (161 UI/L) aldolase (34.2 UI/L) and myoglobin (> $1200 \mathrm{ng} / \mathrm{ml}$ ). The chest radiograph and the electrocardiogram didn't show any significant modifications.

The EMNG demonstrated signs of muscle fiber injury with signs of muscle fiber irritability. 


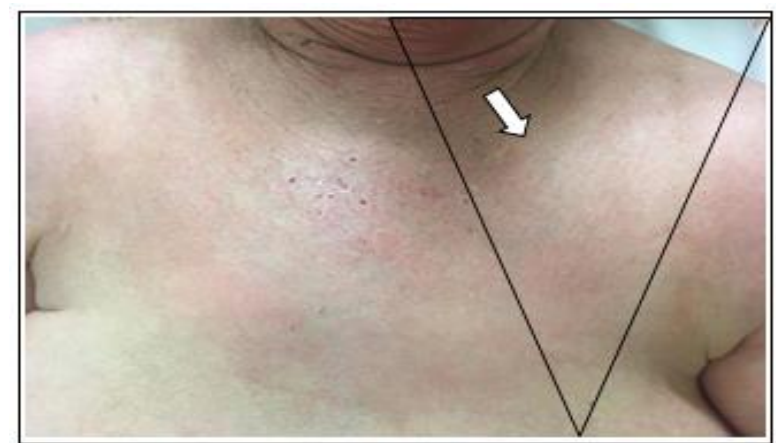

Image-1: Triangular erythema in the neckline $(V$ sign) with impetiginized vesicular-bullous lesions

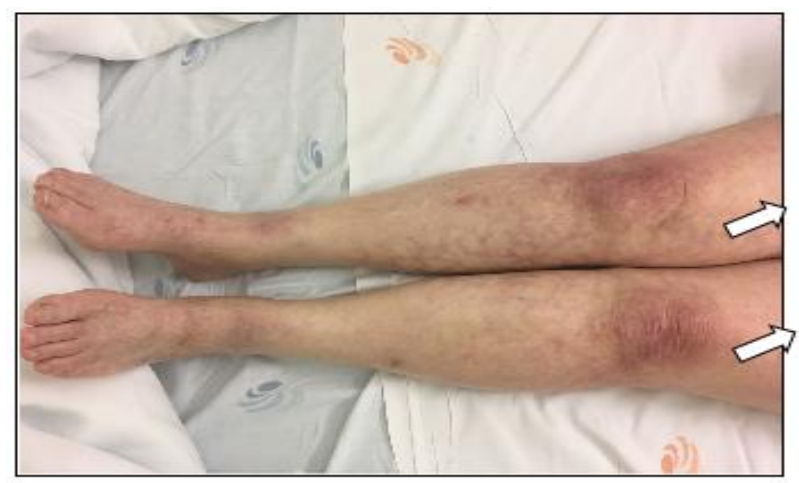

Image-2: Gottron papules in the knees

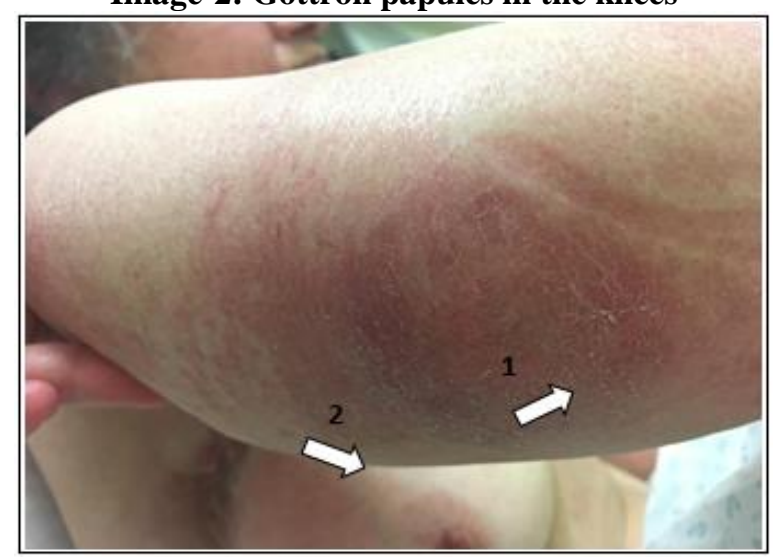

Image-3: Gottron papules in the elbow (arrow 1) and ulcerated lesion in the upper right quadrant of the breast (arrow 2)

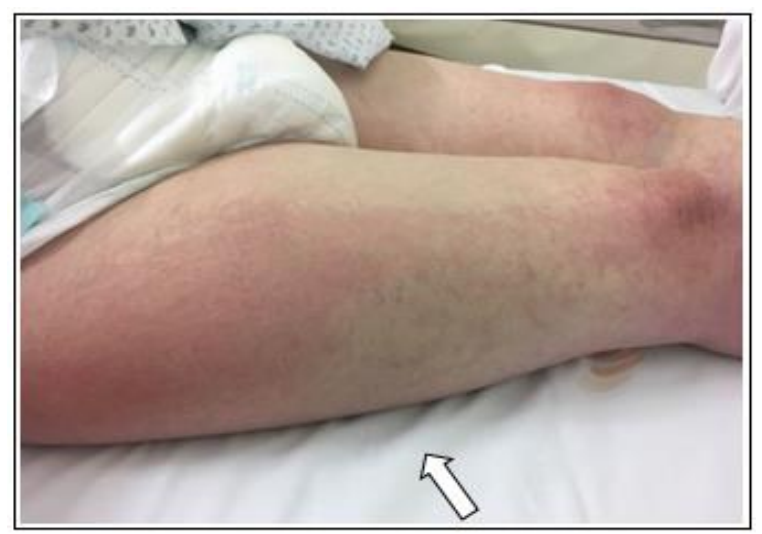

Image-4: Holster sign
The patient underwent a biopsy of the breast lesion for anatomopathological study. Due to the highly suspicious nature of breast cancer, the patient was promptly staged with computed tomography scanner (CT scan) that revealed a nodular formation in the right breast, $28 \mathrm{~mm}$ in diameter, apparently invading the skin at the transition with the axillary region, and another nodular formation with $19.5 \mathrm{~mm}$ in diameter. Smaller adenopathies were also visible in the right axillary region. The bone scintigraphy was normal.

With the start of corticosteroid therapy with methylprednisolone (60 mg/day), the patient showed a slight improvement of the skin lesions, as well as a decrease of muscle and cardiac enzymology markers. However, the anatomopathological result showed an invasive carcinoma, and a palliative hormone therapy was decided based on multidisciplinary consultation meeting.

\section{DISCUSSION}

Dermatomyositis is an idiopathic inflammatory myopathy, with an estimated prevalence rate of approximately 1 per 100000 in the general population [5]. The different forms of DM are more frequent in women than in men, in a ratio 2: 1 [6,7]. Typically it presents with progressive, symmetrical, proximal muscle weakness and characteristic skin lesions such as helitrope rash, Gottron's papules, Gottron's sign, the Vsign and Shawl sign [8].

All patients newly diagnosed with DM should be evaluated for the possibility of an underlying malignancy. Cancer can be diagnosed before, simultaneously with, or after the diagnosis of inflammatory myopathy [9]. It is essential to carry out a neoplastic screening, especially in patients with newly diagnosed DM and aged over 50 years. The relationship between neoplasia and persistent inflammatory myopathy is not understood [10], however it is estimated that $15-30 \%$ of patients with DM have an underlying neoplastic disease [11]. This type of DM represents about $50 \%$ of IIM after 65 years old and less than $10 \%$ before 65 . Clinical factors associated with an increased risk of malignancy include older age at disease onset, dysphagia, evidence of capillary damage on muscle biopsy, cutaneous necrosis, cutaneous leukocytoclastic vasculitis [12]. Adenocarcinomas of the cervix, lung, ovary, pancreas, bladder and stomach are responsible for the most frequent neoplasms associated with inflammatory myopathies $[13,14]$.

Autoimmunity plays an important role in the pathogenesis of inflammatory myopathies, being identified autoantibodies in more than $50 \%$ of patients. The following autoantibodies have been found to confer a positive risk on the development of neoplasia: antitranscriptional intermediary factor- $1 \gamma(\mathrm{TIF}-1 \gamma)$ and antinuclear matrix protein 2 (anti-NPX-2) [15-17]. 
Clara F. Jorge et al; Sch J App Med Sci, Jan, 2022; 10(1): 125-129

According to the criteria of Troyanov and Targoff, the diagnosis of dermatomyositis appears to be probable or even definitive, as the ENMG report was not properly detailed $[5,18]$.

Conforming with the classification criteria of inflammatory myopathies proposed by EULAR/ACR 2017 (Table I), the calculated probability of IIM was $100 \%$, with the diagnosis of DM (without associating the muscle biopsy result). This classification has a diagnostic sensitivity and specificity for IIM of 87 and $82 \%$, respectively, when not associated with muscle biopsy results, and reaches 93 and $88 \%$ when correlated with biopsy [1].

Treatment of the underlying cancer is generally insufficient and DM needs to be treated. This treatment involves use of corticosteroids in first-line, however in this type of IIM, patients often do not respond to corticosteroid therapy, as happened in this patient. The evolution was fulminating and in 15 days, she died after starting the systemic treatment.

\section{CONCLUSION}

Despite the presence of pathognomonic clinical signs of DM, these lesions were not recognized in various medical evaluations, which demonstrates that clinicians are unfamiliar with this disease. Some differential diagnoses were made, like facial cellulitis and drug toxicity, perhaps due to the benignity of the analytical control ab initio. The importance of an exhaustive objective examination in order to unravel the lesions of DM and breast neoplasm, would have allowed a quicker diagnosis, and thus avoided such a quick and fatal outcome.

\section{Conflicts of Interest}

The authors have no conflicts of interest or financial relationships to disclose.

\section{REFERENCE}

1. Lundberg, I. E., Tjärnlund, A., Bottai, M., Werth, V. P., Pilkington, C., de Visser, M., ... \& International Myositis Classification Criteria Project Consortium, the Euromyositis Register, and the Juvenile Dermatomyositis Cohort Biomarker Study and Repository (UK and Ireland). (2017). 2017 European League Against Rheumatism/American College of Rheumatology classification criteria for adult and juvenile idiopathic inflammatory myopathies and their major subgroups. Arthritis \& Rheumatology, 69(12), 2271-2282.

2. Leclair, V., \& Lundberg, I. E. (2018). New myositis classification criteria-what we have learned since Bohan and Peter. Current rheumatology reports, 20(4), 1-8.

3. Qudsiya, Z., Waseem, M. (2021). Dermatomyositis. [Updated 2021 Aug 11]. In:
StatPearls [Internet]. Treasure Island (FL):

StatPearls Publishing; 2021 Jan;

4. Cegatto, L, Reis. V. (2008). Dermatomyositis. An. Bras. Dermatol.

5. Kovacs, S.O., Kovacs, S.C. (1998). Dermatomyositis. J Am Acad Dermatol, 39:899. 920;

6. Oddis, C. V., Conte, C. G., Steen, V. D., \& Medsger Jr, T. A. (1990). Incidence of polymyositis-dermatomyositis: a 20-year study of hospital diagnosed cases in Allegheny County, PA 1963-1982. The Journal of rheumatology, 17(10), 1329-1334.

7. Bohan, A., Peter, J. B., Bowman, R. L., \& Pearson, C. M. Computer-assisted analysis of 153 patients with polymyositis and dermatomyositis.

8. Iaccarino, L., Ghirardello, A., Bettio, S., Zen, M., Gatto, M., Punzi, L., \& Doria, A. (2014). The clinical features, diagnosis and classification of dermatomyositis. Journal of autoimmunity, 48 , 122-127.

9. Chen, Y. J., Wu, C. Y., Huang, Y. L., Wang, C. B., Shen, J. L., \& Chang, Y. T. (2010). Cancer risks of dermatomyositis and polymyositis: a nationwide cohort study in Taiwan. Arthritis research \& therapy, 12(2), 1-7.

10. Tymms, K. E., \& Webb, J. (1985). Dermatopolymyositis and other connective tissue diseases: a review of 105 cases. The Journal of rheumatology, 12(6), 1140-1148.

11. Casciola-Rosen, L., Nagaraju, K., Plotz, P., Wang, K., Levine, S., Gabrielson, E., ... \& Rosen, A. (2005). Enhanced autoantigen expression in regenerating muscle cells in idiopathic inflammatory myopathy. Journal of Experimental Medicine, 201(4), 591-601.

12. Lu, X., Yang, H., Shu, X., Chen, F., Zhang, Y., Zhang, S., ... \& Wang, G. (2014). Factors predicting malignancy in patients with polymyositis and dermatomyostis: a systematic review and meta-analysis. PLoS One, 9(4), e94128.

13. Hill, C. L., Zhang, Y., Sigurgeirsson, B., Pukkala, E., Mellemkjaer, L., Airio, A., ... \& Felson, D. T. (2001). Frequency of specific cancer types in dermatomyositis and polymyositis: a populationbased study. The Lancet, 357(9250), 96-100.

14. Bivalacqua, T. J., Alphs, H., Aksentijevich, I., Schaeffer, E. M., \& Schoenberg, M. P. (2007). Paraneoplastic polyarthritis from non-small-cell lung cancer metastatic to the bladder. Journal of clinical oncology, 25(18), 2621-2623.

15. Calvão, J., Azeiteiro, A. R. I., \& Gonçalo, M. (2019). A importância dos novos autoanticorpos específicos da dermatomiosite. Journal of the Portuguese Society of Dermatology and Venereology, 77(1), 15-24.

16. Kaji, K., Fujimoto, M., Hasegawa, M., Kondo, M., Saito, Y., Komura, K., ... \& Takehara, K. (2007). Identification of a novel autoantibody reactive with 155 and $140 \mathrm{kDa}$ nuclear proteins in patients with 
Clara F. Jorge et al; Sch J App Med Sci, Jan, 2022; 10(1): 125-129

dermatomyositis: an association with malignancy. Rheumatology, 46(1), 25-28.

17. Chinoy, H., Fertig, N., Oddis, C. V., Ollier, W. E., \& Cooper, R. G. (2007). The diagnostic utility of myositis autoantibody testing for predicting the risk of cancer-associated myositis. Annals of the rheumatic diseases, 66(10), 1345-1349.

18. Guerne, P. A. (2008). Myosites: donnees actuelles sur la classification, le diagnostic et le traitement. Revue médicale suisse, (149), 718-727. 